\title{
Path Analysis on the Biopsychosocial Determinants of Quality of Life among Children with Cerebral Palsy
}

\author{
Alinda Nur Ramadhani'), Rita Benya Adriani'), Harsono Salimo3) \\ 1)Masters Program in Public Health, Universitas Sebelas Maret \\ ${ }^{2)}$ Department of Speech and Occupational Therapy, \\ School of Health Polytechnics Surakarta \\ 3)Department of Pediatrics, Dr. Moewardi Hospital, Surakarta
}

\begin{abstract}
Background: Cerebral palsy (CP) is group of disorders characterized by long-term disabilities that affect the quality of life (QoL) of both patients and those caring for them. This study aimed to examine biopsychosocial determinants of quality of life among children with cerebral palsy, using path analysis model.

Subjects and Method: A cross-sectional study was conducted at Fondation for the Care of Disable Children (YPAC) and Pediatric Neurodevelopmental Therapy Center, Surakarta, Central Java, from April to May 2018. A sample of 110 children with cerebral palsy was selected for this study by simple random sampling. The dependent variable was quality of life. The independent variables were gross motoric skill, parental stress, family support, and social support. Data on quality of life was measured by Cerebral Palsy Quality of Life (CP-QOL) questionnaire. The other data were collected by questionnaire and analyzed by path analysis.

Results: Quality of life of children with cerebral palsy increased with better gross motor $(b=2.79$; $95 \% \mathrm{CI}=1.54$ to $4.03 ; \mathrm{p}<0.001)$, strong family support $(\mathrm{b}=1.25 ; 95 \% \mathrm{CI}=0.26$ to $2.24 ; \mathrm{p}=0.013)$, and strong social support $(b=0.99 ; 95 \% C I=0.014$ to $1.97 ; p=0.047)$. Quality of life of children with cerebral palsy indirectly decreased with high parental stress $(b=-1.55 ; 95 \% \mathrm{CI}=-2.38$ to -0.72 ; $\mathrm{p}<0.001$ ).

Conclusion: Quality of life of children with cerebral palsy increases with better gross motor, strong family support, and strong social support, but indirectly decreases with high parental stress.
\end{abstract}

Keywords: cerebral palsy, quality of life, gross motor, family support, parental stress, children

\section{Correspondence:}

Alinda Nur Ramadhani. Masters Program in Public Health, Universitas Sebelas Maret, Jl. Ir. Sutami 36 A, Surakarta 57126, Central Java. Email: aramadhani95@gmail.com

\section{BACKGROUND}

Cerebral Palsy is defined as a set of permanent disorders of the development of motion and posture that cause the limitation of activity, caused by non-progressive disorder that occurs in the infant's brain or fetus that develops and occurs in childhood. Motor disturbances in cerebral palsy are often accompanied by sensory, perceptual, cognitive, communication and behavioral disorders due to secondary musculoskeletal disorders" (Rossenbaum et al., 2007). Other disorders that occur in children with cere- bral palsy are visual, auditory, linguistics and communication disorders, mental retardation, epilepsy and decreased daily activity (Delacy \& Reid, 2016; Jeffries et al., 2016; Reddihough et al., 2013).

These disorders affect on various aspects of the child's life including physical health, social welfare of the emotions, participation in daily activities, and quality of life (Colver et al., 2014; Rosenbaum et al., 2007.

Several studies have revealed that the quality of life of children and adolescents of 
cerebral palsy show similar values to the general population except in the domain of social participation and motor function (Colver et al., 2015; Dickinson et al., 2007) Factors affecting quality of life children of cerebral palsy are highly multidimensional and vary across biological, psychological, and social aspects (Chen et al., 2014). Parental stress, psychological problems, pain and motor impairment in children with cerebral palsy are known to be predictors of deteriorating quality of life (Colver et al., 2015; Boling et al., 2013).

In Indonesia, there has not been much research on factors related to the quality of life of children with cerebral palsy. This study is expected to add to the reference knowledge in the study of the quality of life of children with cerebral palsy.

\section{SUBJECTS AND METHOD}

\section{Study Design}

This was an analytic observational study by a cross-sectional design. The study was conducted at Fondation for the Care of Disable Children (YPAC) and Pediatric Neurodevelopmental Therapy Center, Surakarta, Central Java, from April to May 2018.

\section{Population and Samples}

The target population in the study was all children of cerebral palsy aged 4-12 years. A sample of 110 children with cerebral palsy aged 4-12 years was selected by simple random sampling.

\section{Study Variables}

The dependent variable was the quality of life of children with cerebral palsy. The independent variables were gross motor skill, parental stress, family support, and social support.

\section{Operational Definition of variables}

Quality of life was defined as an assessment of the subjective well-being of the indivi- dual covering the health and non-health fields. The data were collected by questionnaire. The measurement scale was continuous, but for the purpose of data analysis, it was transformed into dichotomous, coded $\mathrm{o}$ for poor and 1 for good.

Gross motor skill was defined as the ability of motion and body coordination that involve the work of large muscles such as standing, walking, running, jumping, and throwing. The data were measured by questionnaire. The measurement scale was continuous, but for the purpose of data analysis, it was transformed into dichotomous, coded o for poor and 1 for good.

Parental stress was defined as psychological stress conditions experienced by parents during child care. The data were measured by questionnaire. The measurement scale was continuous, but for the purpose of data analysis, it was transformed into dichotomous, coded o for low and 1 for high.

Family support was defined as a form of behavior performed by the family in the form of informational, emotional, instrumental, and assessment support. The data were measured by questionnaire. The measurement scale was continuous, but for the purpose of data analysis, it was transformed into dichotomous, coded o for weak and 1 for strong.

Social support was defined a form of behavior carried out by the social environment such as relatives, close friends, spouses, coworkers, and neighbors, in the form of informational, emotional, instrumental, and assessment support. The data were measured by questionnaire. The measurement scale was continuous, but for the purpose of data analysis, it was transformed into dichotomous, coded o for weak and 1 for strong. 


\section{Data Analysis}

The data analysis techniques employed univariate, bivariate, and multivariate analyzes. Univariate analysis aims to explain the characteristics of each variable.

Bivariate analysis aims to analyze the relationship of two variables using SPSS with chi square test. Multivariate analysis was done using path analysis with program Stata 13 to know the relation of the independent variable to the dependent variable and to know the amount of relation on that variable.

\section{Ethical Clearance}

The ethics of this study included informed consent, anonymity, confidentiality, beneficence, and ethical clearance that have been obtained from the medical research ethic committee of Dr. Moewardi hospital, Surakarta with Number: 377/ III/ HREC/ 2018.

\section{RESULTS}

\section{Univariate Analysis}

Table 1 showed the characteristics of cerebral palsy type, consisting of spastic (66.4\%), athetoid (19.1\%), and ataxia (14.5\%). Cerebral palsy children with poor quality of life consisted of $62(56.4 \%)$ and the good quality of life was 48 (43.6\%).

Cerebral palsy children with good gross motor skills were 31 (28.2\%) and poor gross motor abilities were 79 (71.8\%). Children with cerebral palsy parents have high stress level of $63(57.3 \%)$ and low stress level of 47 (42.7\%).

Cerebral palsy children with strong family support were 59 (53.6\%) and weak family support was about 51 (46.4\%). Child cerebral palsy with strong social support was about $49(44.5 \%)$ and weak social support of 61 (55.5\%).
Table 1. The Results of Univariate Analysis

\begin{tabular}{lcc}
\hline \multicolumn{1}{c}{ Variables } & n & \% \\
\hline Quality of Life & 62 & 56.4 \\
Poor & 48 & 43.6 \\
Good & & \\
Type of Cerebral Palsy & 73 & 66.4 \\
Spastic & 21 & 19.1 \\
Athetoid & 16 & 14.5 \\
Ataxia & & \\
Gross Motoric Skill & 31 & 28.2 \\
Good & 79 & 71.8 \\
Poor & & \\
Parental stress & 63 & 57.3 \\
High & 47 & 42.7 \\
Low & & \\
Family Support & 51 & 46.4 \\
Weak & 59 & 53.6 \\
Strong & & \\
Social Support & 61 & 55.5 \\
Weak & 49 & 44.5 \\
\hline Strong & & \\
\hline
\end{tabular}

\section{Bivariate Analysis}

Table 2 shows the association of gross motor, parental stress, family support, and social support, on quality of life of children with cerebral palsy.

Table 2 shows that good gross motoric skill increased quality of life of children with cerebral palsy $(\mathrm{OR}=18.64 ; 95 \% \mathrm{CI}=$ 5.89 to $59.62 ; \mathrm{p}<0.001)$.

Strong family support increased quality of life of children with cerebral palsy $(\mathrm{OR}=5.08 ; \quad 95 \% \quad \mathrm{CI}=0.14$ to 0.69 ; $\mathrm{p}<0.001)$.

Strong social support increased quality of life of children with cerebral palsy $\mathrm{OR}=3.77 ; 95 \% \mathrm{CI}=2.21$ to $11.69 ; \mathrm{p}=$ 0.001).

Strong parental stress decreased quality of life of children with cerebral palsy $(\mathrm{OR}=0.31 ; 95 \% \mathrm{CI}=0.14$ to $0.69 ; \mathrm{p}=$ o.006). 
Journal of Maternal and Child Health (2018), 3(4): 301-307

https://doi.org/10.26911/thejmch.2018.03.04.08

Table 2. Bivariate analysis on the effects of gross motor, parental stress, family support, and social support, on the quality of life among children with cerebral Palsy

\begin{tabular}{|c|c|c|c|c|c|c|c|c|c|}
\hline \multirow{3}{*}{$\begin{array}{l}\text { Independent } \\
\text { Variables }\end{array}$} & \multicolumn{6}{|c|}{ Quality of life } & \multirow{3}{*}{ OR } & \multirow{3}{*}{ 95\% CI } & \multirow{3}{*}{$\mathbf{p}$} \\
\hline & \multicolumn{2}{|c|}{ Poor } & \multicolumn{2}{|c|}{ Good } & \multicolumn{2}{|c|}{ Total } & & & \\
\hline & $n=62$ & $\%$ & $n=48$ & $\%$ & $\mathbf{n}=110$ & $\%$ & & & \\
\hline \multicolumn{10}{|c|}{ Gross Motoric Skill } \\
\hline Poor & 58 & 93.5 & 21 & 43.8 & 79 & 100 & \multirow[t]{2}{*}{18.64} & 5.89 to & \multirow[t]{2}{*}{$<0.001$} \\
\hline Good & 4 & 6.5 & 27 & 56.3 & 31 & 100 & & 59.62 & \\
\hline \multicolumn{10}{|l|}{ Parental Stress } \\
\hline High & 43 & 69.4 & 20 & 41.7 & 63 & 100 & \multirow[t]{2}{*}{0.31} & 0.14 to & \multirow[t]{2}{*}{0.006} \\
\hline Low & 19 & 30.6 & 28 & 58.3 & 47 & 100 & & 0.69 & \\
\hline \multicolumn{10}{|l|}{ Family Support } \\
\hline Weak & 39 & 62.9 & 12 & 25 & 51 & 100 & \multirow[t]{2}{*}{5.08} & 2.21 to & \multirow[t]{2}{*}{$<0.001$} \\
\hline Strong & 23 & 37.1 & 36 & 75 & 59 & 100 & & 11.69 & \\
\hline \multicolumn{10}{|l|}{ Social Support } \\
\hline Weak & 43 & 69.4 & 18 & 37.5 & 61 & 100 & \multirow[t]{2}{*}{3.77} & 1.70 to & \multirow[t]{2}{*}{0.001} \\
\hline Strong & 19 & 30.6 & 30 & 62.5 & 49 & 100 & & 8.35 & \\
\hline
\end{tabular}

\section{The Results of Path Analysis}

Based on the results of path analysis, the number of observed variables were 5 , endogenous variable $=1$, and exogenous variables $=4$. The degree of freedom $(\mathrm{df})$ value was 5 (over identified), so it can conclude that path analysis can be performed.

Table 3 showed that there was a direct and positive relationship between family support and quality of life which was statistically significant $(b=1.25 ; 95 \% \mathrm{CI}=0.26$ to
2.24; $\mathrm{p}=0.013)$. Children who have strong family support increased the logodd of good quality of life by 1.25 units than children with weak family support.

There was a direct and positive relationship between social support and quality of life $(b=0.99 ; 95 \% \mathrm{CI}=0.014$ to $1.97 ; \mathrm{p}=$ o.047). Children with strong social support increased the logodd of good quality of life by 0.99 unit than children with weak social support.

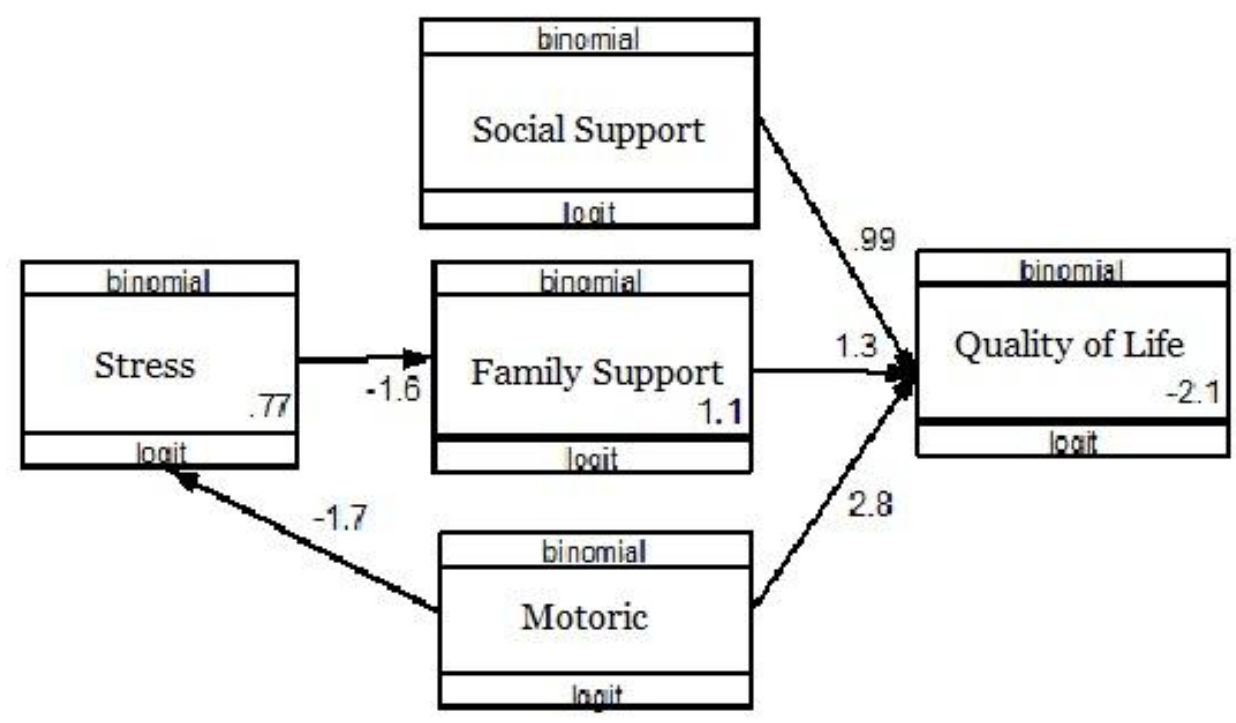

Figure 1. Structural Model of Path Analysis with Estimation 
There was direct and positive relationship between gross motoric skill and quality of life $(b=2.79 ; 95 \% \mathrm{CI}=1.54$ to 4.03; $\mathrm{p}<0.001)$. Children with good gross motoric skill increased the logodd of good quality of life by 2.79 units than children with poor gross motoric skill.

Gross motoric skill was negatively associated with parental stress $(b=-1.66$;

Table 3. The Results of Path Analysis

\begin{tabular}{|c|c|c|c|c|c|c|}
\hline \multirow{2}{*}{$\begin{array}{c}\text { Dependent } \\
\text { Variable }\end{array}$} & \multirow{2}{*}{\multicolumn{2}{|c|}{$\begin{array}{c}\text { Independent } \\
\text { Variable }\end{array}$}} & \multirow[b]{2}{*}{$\mathbf{b}$} & \multicolumn{2}{|c|}{$95 \% \mathrm{CI}$} & \multirow[b]{2}{*}{$\mathbf{p}$} \\
\hline & & & & $\begin{array}{l}\text { Upper } \\
\text { Limit }\end{array}$ & $\begin{array}{c}\text { Lower } \\
\text { Limit }\end{array}$ & \\
\hline Direct Effect & & & & & & \\
\hline Quality of Life & $\leftarrow$ & Family Support & 1.25 & 0.26 & 2.24 & 0.013 \\
\hline Quality of Life & $\leftarrow$ & Social Support & 0.99 & 1.01 & 1.97 & 0.047 \\
\hline Quality of Life & $\leftarrow$ & Gross Motoric Skill & 2.79 & 1.55 & 4.03 & $<0.001$ \\
\hline Indirect Effect & & & & & & \\
\hline Family Support & $\leftarrow$ & Parental Stress & -1.55 & -2.24 & -0.73 & $<0.001$ \\
\hline Parental Stress & $\leftarrow$ & Gross Motoric Skill & -1.66 & -2.57 & -0.75 & $<0.001$ \\
\hline
\end{tabular}

\section{DISCUSSIONS}

\section{The effect of family support on quality of life of children with cerebral palsy}

The result of analysis showed that there was a relationship between family support and quality of life among children with cerebral palsy. The result of this study was in line with a study by Mohammed et al. (2016), which stated that family factor was associated to children's quality of life.

The forms of family support including information, emotional, instrumental, and assessment support. Strong information support including basic knowledge of causes, the disturbances in the condition of cerebral palsy, and care management which helped the parents to know the needs of their children which in accordance with the disturbance condition.

Instrumental support was obtained from the fulfillment of treatment needs. Instrumental support was in the form of material related to family's socio-economic conditions. Good family socio-economic
95\% CI=-2.57 to $-0.754 ; \mathrm{p}<0.001)$. Children with good gross motoric skill reduced parental stress.

There was an indirect association between parental stress and quality of life through family support. Higher parental stress reduced family support $(b=-1.55$; $95 \% \mathrm{CI}=-2.38$ to $-0.72 ; \mathrm{p}<0.001)$. conditions might affect the level of instrumental support. For example, cerebral palsy children with adequate instrumental needs (access to therapy and utility needs) allowed the children to receive good treatment, improved the function of daily activeties, and children's participation. This enhancement would affect children's quality of life.

\section{The effect of social support on quality of life of children with cerebral palsy}

The result of analysis showed that there was a relationship between social support and quality of life among children with cerebral palsy. Strong social support increased quality of life among among children with cerebral palsy.

\section{The effect of gross motoric skill on quality of life of children with cerebral palsy}

The result of analysis showed that there was a direct relationship between gross motoric skill and quality of life among children with cerebral palsy. 
The result of this study was in line with a study by Chen et al. (2014); Surender et al. (2016); Badia et al. (2016); Mohammed et al. (2016), which stated that there was a relationship between gross motoric function and quality of life. Cerebral palsy children who have low level of gross motoric function were more likely to have poor quality of life. Gross motoric functions were associated with almost all domains of quality of life such as the domain of participation, physical health, physical function, and emotional welfare.

\section{The effect of parental stress on quality of life of children with cerebral palsy}

There was a relationship between parental stress and quality of life among children with cerebral palsy.

Previous studies showed that caring for children with long-term disability. Stated that the level of stress was higher than common parents. High parental stress level was associated to children's quality of life. Stress management and coping strategies in parents might affect children's quality of life conditions increased parental stress level (Chen et al., 2014; Mohammed et al., 2016).

The results of this study conclude that gross motor skill, parental stress, family support, and social support were associated with the quality of life of children with cerebral palsy.

Several interventions can be made to improve the quality of life among children with cerebral palsy such as improving the focus of impairment care which associated with cerebral palsy and the provision of adequate health services. In terms of family, the quality of life among children with cerebral palsy can be enhanced by improving parental coping strategies, parental assistance, and involving teams (doctors, physiotherapists, or teachers) in childcare programs.

\begin{tabular}{l}
\hline REFERENCES \\
\hline Badia M, Begona Orgaz M, Gomez-Vela M, \\
Verdugo MA, Ullan AM, \& Longo E. \\
(2016). Do environmental barriers \\
affect the parent-reported quality of \\
life of children and adolescents with \\
cerebral palsy? Research in Develop- \\
mental Disabilities, 49-50: 312-321. \\
https://doi.org/10.1016/j.ridd.2015.- \\
12.011
\end{tabular}

Boling S, Tarja V, Helena M, Wivi F, Ilona, AR, Leena $H$ (2013). Measuring quality of life of Finnish children with Palsi Serebralis. J Pediatr Rehabilit Med, 6: 121-7.

Chen KL, Tseng MH, Shieh JY, Lu L, Huang CY (2014). Determinants of quality of life in children with cerebral palsy: A comprehensive biopsychosocial approach. Research in Developmental Disabilities, 35(2), 520-528. https://doi.org/10.1016/j.ridd.2013.1 2.002

Colver A, Fairhurst C, Pharoah POD (2014). Cerebral palsy. The Lancet, 383 (9924), 1240-1249. https://doi.org/10.1016/S0140-6736(13)61835-8

Colver A, Rapp M, Eisemann N, Ehlinger V, Thyen U, Dickinson HO, et al. (2015). Self-reported quality of life of adolescents with cerebral palsy: A crosssectional and longitudinal analysis. The Lancet, 385(9969), 705-716. https://doi.org/10.1016/So140-6736(14)61229-o

Delacy MJ, Reid SM (2016). Profile of associated impairments at age 5 years in Australia by cerebral palsy subtype and Gross Motor Function Classification System level for birth years 1996 to 2005. Developmental Medicine \& Child Neurology, 58, 50-56. 
https://doi.org/10.1111/dmcn.13012

Dickinson HO, Parkinson KN, Ravens-Sieberer U, Schirripa G, Thyen U, Arnaud $C$ (2007). Self-reported quality of life of 8-12-year-old children with cerebral palsy: a multi-centre cross-sectional European Study. Lancet, 369(9580), 2171-2178.

Jeffries L, Fiss A, McCoy SW, Bartlett D J. (2016). Description of Primary and Secondary Impairments in Young Children With Cerebral Palsy. Pediatric Physical Therapy, 28(1), 7-14. https://doi.org/10.1097/PEP.oooooooooo 000221

Mohammed FS, Ali S, \& Mustafa MA. (2016). Quality of life of cerebral palsy patients and their caregivers: A cross sectional study in a rehabilitation center Khartoum-Sudan (2014-2015). Journal of Neurosciences in Rural Practice, 7(3), 355. https://doi.org/10.4103/0976-3147.182778

Rapp M, Eisemann N, Arnaud C, Ehlinger V, Fauconnier J, Marcelli M, ... Thyen, U. (2017). Predictors of parent-reported quality of life of adolescents with cerebral palsy: A longitudinal study. Research in Developmental Disabilities, 62, 259-270.https://doi.org/10.1016/j.ridd.2016.12.005

Reddihough DS, Jiang B, Lanigan A, Reid SM, Walstab JE, \& Davis E. (2013). Social outcomes of young adults with cerebral palsy. Journal of Intellectual and Developmental Disability, 38(3), 215-222. https://doi.org/10.3109/13668250.2013.788690.

Rosenbaum P, Paneth N, Leviton A, Goldstein M, Bax M, Damiano D,... Jacobsson B. (2007). A report: The definition and classification of cerebral palsy April 2006. Developmental Medicine and Child Neurology, 49 (SUPPL.109), 8-14. https://doi.org/10.1111/j.1469-8749.2007.tb12610.x

Surender S, Gowda V, Sanjay K, Basavaraja G, Benakappa N, \& Benakappa A. (2016). Caregiver-reported health-related quality of life of children with cerebral palsy and their families and its association with gross motor function: A South Indian study. Journal of Neurosciences in Rural Practice, 7(2), 223. https://doi.org/10.4103/0976-3147.178657 